\title{
PROGRAMA SEGUNDO TEMPO E O PAPEL DAS PREFEITURAS NA SUA DIFUSÃO'
}

\author{
Edmilson Santos dos Santos \\ Universidade Federal do Vale do São Francisco, Petrolina, Pernambuco, Brasil. \\ Jean Carlo de Sá Andrade \\ Universidade Federal do Vale do São Francisco, Petrolina, Pernambuco, Brasil. \\ Roberto Silva Santos \\ Universidade Federal do Vale do São Francisco, Petrolina, Pernambuco, Brasil.
}

\begin{abstract}
Resumo
Passados dez anos de implementação do Programa Segundo Tempo, pelo Ministério do Esporte, e, dada sua importância como uma política associada ao bem-estar infantil e juvenil, torna-se necessário examinar o papel das prefeituras na sua difusão, objetivo principal deste artigo. O estudo, de natureza descritiva, procurou contemplar o desempenho regional e a participação junto aos municípios vulneráveis. Os resultados obtidos indicam que os incentivos à descentralização se apresentam de forma ainda muito tímida, não mobilizando a atenção dos gestores municipais. Nesse caso, a desatenção dos gestores compromete o bem-estar infantil e juvenil e promove o acirramento da desigualdade de acesso ao desporto educacional e a melhoria da qualidade de vida.
\end{abstract}

Palavras chave: Política Pública. Esporte. Implementação.

\section{Introdução}

Os estudos sobre o impacto de programas federais de esporte educacional na escala local ainda são muito incipientes. Passados 10 anos de implementação do Programa Segundo Tempo pelo Ministério do Esporte, e dada sua importância como uma política associada ao bem-estar infantil e juvenil (promoção do desporto educacional), torna-se necessário examinar o papel das prefeituras na sua difusão ${ }^{2}$.

Nesse sentido, este estudo, de natureza descritiva, buscou analisar a participação das prefeituras na difusão do PST. Como objetivos específicos: identificar o impacto da difusão na escala regional e estadual e a participação dos municípios vulneráveis. Para isso, construímos um banco de dados com informação proveniente de diferentes fontes. Como a unidade de análise é a prefeitura, consideramos todas aquelas que, durante o período de 2003 a 2012, conveniaram com o Ministério do Esporte pelo menos uma vez.

\footnotetext{
${ }^{1}$ Este trabalho é produto de projeto de pesquisa financiado pela Fundação de Amparo à Ciência e Tecnologia do Estado de Pernambuco (Facepe).

${ }^{2}$ Para análise do tema da difusão, no sentido de compreender como uma política vai se reproduzindo em outros ambientes ao longo do tempo, ver Berry e Berry (1999).
}

Pensar a Prática, Goiânia, v. 17, n. 4, out./dez. 2014 
Os dados referentes à localização regional das prefeituras foram coletados diretamente no site do Instituto Brasileiro de Geografia e Estatística (IBGE). O marcador de vulnerabilidade utilizado foi o Índice de Exclusão Social de Pochmann e Amorim (2005).

Para a análise aqui pretendida, organizamos o trabalho em três seções. Na primeira, apresentamos de forma sucinta os antecedentes do Programa Segundo Tempo e como ele está organizado atualmente. Na segunda, abordamos alguns aspectos que aproximam o programa de um projeto maior de atenção integral à criança, a despeito de não ter sido concebido de forma articulada com uma política de educação integral. Por último, analisamos de que forma a participação das prefeituras municipais no desenho federalista ajudou a diminuir (ou não) a desigualdade de acesso ao desporto educacional e sua influência na melhoria da qualidade de vida das crianças brasileiras.

\section{Programa Segundo Tempo: breve histórico}

O Ministério do Esporte (ME), como órgão exclusivo da gestão esportiva, foi criado pela Medida Provisória no 103, de 1\%/1/2003, durante o primeiro ano da gestão do Presidente Luiz Inácio Lula da Silva. Sua criação surge com o desafio de centralizar a política pública de esporte, como assinalam Alves e Pieranti (2007). Entre as primeiras ações do $\mathrm{ME}$, no campo do esporte educacional, está a continuidade dada à política de atenção às crianças, principalmente as mais vulneráveis, implementada ainda durante o governo do Presidente Fernando Henrique Cardoso. Esse legado, além de permitir desencadear ações já no início do governo, contribuiu na criação de outras políticas, como o Programa Bolsa Família, por exemplo. A ideia central foi a de condensar programas já existentes a partir da criação de um novo, com capacidade de ampliar o atendimento.

Nesse sentido, o Programa Segundo Tempo (PST) tem uma história em termos de política pública. Ele surge de forma incremental a partir dos programas Esporte na Escola e Esporte Solidário (FERREIRA; CASSIOLATO; GONZALEZ, 2009). O primeiro destinava-se a desenvolver a prática esportiva nos alunos de escolas públicas. O segundo estava direcionado à garantia do acesso à atividade esportiva às comunidades carentes.

O Programa Esporte na Escola foi criado no segundo semestre de 2001, com o objetivo de democratizar o acesso à prática esportiva, de forma a contribuir com o desenvolvimento integral dos estudantes. Ele nasce com uma meta bastante ambiciosa: implantar cerca de 100 mil núcleos esportivos em todo o território nacional e atingir 36 milhões de estudantes em 12 anos. Para sua implementação foram realizadas parcerias com o Ministério da Educação, Ministério da Defesa e organizações não governamentais.

O Programa Esporte Solidário é mais antigo, foi implementado em 1996. Surge com o objetivo de desenvolver ações em regiões carentes, a fim de diminuir a exposição ao risco social. A faixa etária de atendimento era de 7 a 24 anos. O programa chegou a alcançar 26 estados em 2001, com 857 núcleos e 239 mil pessoas atendidas. Ciente das dificuldades de infraestrutura para o seu desenvolvimento (as regiões mais pobres carecem também de infraestrutura adequada à prática esportiva), o programa também pactuou com a Caixa Econômica Federal a construção de 1.771 espaços esportivos e a modernização de outros 78 para execução de suas atividades.

O PST acabou unificando dois objetivos: atender crianças matriculadas no sistema público de ensino no contraturno escolar e, preferencialmente, aquelas em situação de 
vulnerabilidade ou risco social. O programa surge, portanto, com uma forte preocupação de combate à exclusão social, política prioritária do Governo Lula, visando garantir atenção à criança no turno inverso. Em que pese a preocupação com o turno inverso, o programa nasce desvinculado de uma política mais ampla de educação integral. Como veremos mais adiante, esse dado nos permite refletir sobre uma velha narrativa que vê o tempo ocioso de determinadas crianças (as mais pobres) como um problema social.

Coube à Secretaria Nacional de Esporte Educacional (SNEED/ME) ${ }^{3}$, através do Departamento de Esporte Escolar e Identidade Cultural, o compromisso de formular e implementar políticas de esporte educacional (entre elas estava o PST). E é justamente o entendimento sobre o significado do esporte educacional que tem produzido importantes implicações à análise da política pública pela ambiguidade que carrega (ZAHARIADIS, 2007).

O programa surge com uma preocupação redistributiva muito forte, na esteira de outros projetos do Governo Lula (ALMEIDA, 2004). Sua agenda social foi a principal marca que o governo procurou imprimir em suas ações. A democratização do desporto educacional a que se propõe o programa passa, primeiro, pelas áreas de vulnerabilidade social.

\section{Atenção integral à criança e o papel do PST}

No art. 34 da LDB está fixado que "A jornada escolar no ensino fundamental incluirá pelo menos quatro horas de trabalho efetivo em sala de aula, sendo progressivamente ampliado o período de permanência na escola". O $\S 2^{\circ}$ acrescenta que "O ensino fundamental será ministrado progressivamente em tempo integral, a critério dos sistemas de ensino". A garantia das quatro horas e sua ampliação constitui objetivo a ser perseguido pelo Estado. Dentro dessa carga horária, o desporto aparece, por meio do ensino da educação física, como um componente curricular obrigatório e, no turno inverso, como uma ferramenta que possibilita a ampliação das experiências desportivas.

É importante destacar que o projeto de educação integral, ao transcender os aspectos puramente cognitivos (GUARÁ, 2006), incorpora o desporto de uma forma muito positiva. O Plano Nacional de Educação (2000) define que a ampliação da jornada de estudo deve possibilitar "[...] orientação no cumprimento dos deveres escolares, prática de esporte, desenvolvimento de atividades artísticas e alimentação adequada, no mínimo em duas refeições" [grifo nosso]. Nesse sentido, o desporto que aqui está sendo pautado difere daquele que aparece como obrigação a ser contemplada pelas aulas de educação física: a busca utilitária pela aprendizagem e pelo desenvolvimento de algum desporto.

O desporto, por sua capacidade agregadora, mobilizadora e socializadora, não pode servir como isca para objetivos que não se constituem no campo do direito ${ }^{4}$. Nesse sentido, parece-nos muito contraditório apresentar como objetivos de programas que buscam garantir a atenção integral, como o Programa Segundo Tempo (PST) - cabe ressaltar que ele não é o único -, o cuidado com o tempo ocioso da criança e do adolescente. Se

\footnotetext{
${ }^{3}$ Hoje denominada Secretaria Nacional de Esporte, Educação, Lazer e Inclusão Social (Snelis).

${ }^{4}$ Bourdieu (1983) aponta que o esporte, na sua origem moderna, já era pensado como uma estratégia para o controle dos estudantes das public schools.
}

Pensar a Prática, Goiânia, v. 17, n. 4, out./dez. 2014 
entendermos o tempo ocioso como um direito a ser preservado (art. 6을 $\mathrm{CF}$ ), a questão não pode ser colocada sob o prisma do Estado punitivo - vigilância intensiva (SEIBEL, 2005). O cuidado na formação integral é que exige a oferta de atividades que possam enriquecer culturalmente a vida das crianças e dos jovens, e não a tentativa de regrar a vida das crianças e dos jovens moradores das periferias que "exigem" controle e vigilância. $\mathrm{O}$ PST configura-se então como importante ferramenta que visa garantir direitos às crianças, principalmente às mais vulneráveis. Para alcançar esse objetivo, o programa propõe descentralizar recursos, mediante convênios firmados com o Ministério, para governos estaduais, prefeituras ou organizações da sociedade civil. Seu objetivo principal é democratizar o acesso ao desporto educacional.

\section{Descentralização de programas na federação brasileira}

A política pública na área social tem como premissa básica a democratização do acesso a um determinado bem social, de forma a diminuir a desigualdade existente em sua distribuição na sociedade. Essa preocupação está expressa de maneira explícita no Programa Segundo Tempo do Ministério do Esporte.

O programa se coloca como um forte aliado na diminuição da desigualdade regional e social. Por conseguinte, a justiça alocativa está diretamente associada ao aumento de investimentos nas áreas em que se encontra o público-alvo do programa, quais sejam as localidades mais vulneráveis, que, historicamente, são portadoras de múltiplas desvantagens e severas assimetrias, principalmente nas regiões Norte e Nordeste.

Nos dez anos de implantação do programa, apenas 435 municípios do território nacional assinaram termo de convênio com o Ministério do Esporte, o que representa menos de $10 \%$ do total. Podemos extrair desse dado algumas hipóteses, tais como: as prefeituras tiveram poucos estímulos à adesão (ganhos pouco atrativos à adesão), algumas dificuldades (principalmente operacionais) de aderir ao programa ou ele (o PST) não compõe o pacote de preferências dos governos municipais.

De toda forma, os resultados demonstram que as prefeituras não se tornaram, ao longo do período aqui analisado, parceiros estratégicos do governo federal na difusão do PST, e tampouco conseguiram diminuir a desigualdade regional de acesso ao serviço ofertado pelo programa. Considerando apenas aquelas prefeituras que se conveniaram ao programa, as regiões mais desenvolvidas, Sul e Sudeste, foram responsáveis por mais de $62,53 \%$ da difusão. Nesse aspecto, o resultado acabou por reproduzir a desigualdade distributiva regional a qual se propõe a combater, como pode ser observado na Tabela 1. 


\section{Tabela 1 - Diferença do percentual de representação do número de prefeituras por região pelo percentual de prefeituras por região que difundiram o PST}

\begin{tabular}{llllcl}
\multicolumn{1}{r}{ Região } & Prefeituras & \multicolumn{1}{c}{$\%$} & \multicolumn{1}{c}{ Adesão } & $\%$ & $\begin{array}{c}\text { Diferença } \\
(\mathrm{pp})\end{array}$ \\
Norte & 449 & 8,07 & 16 & 3,68 & $\downarrow 4,39$ \\
Nordeste & 1794 & 32,24 & 121 & 27,82 & $\downarrow 4,42$ \\
Sudeste & 1668 & 29,97 & 189 & 43,45 & $\uparrow 13,48$ \\
Sul & 1189 & 21,37 & 83 & 19,08 & $\downarrow 2,29$ \\
Centro-Oeste & 465 & 8,36 & 26 & 5,98 & $\downarrow 2,38$
\end{tabular}

Fonte: IBGE e Programa Segundo Tempo do Ministério do Esporte (2013).

O Brasil já experimentou uma variedade de arranjos federativos, como aponta Souza (2005). Mais do que compreender esse histórico, a questão que se coloca é tentar identificar que variáveis caracterizam o modelo brasileiro e seus impactos na distribuição de recursos. As assimetrias entre os níveis de governo (desempenho fiscal, por exemplo) produzem diferentes cenários à distribuição e redistribuição de recursos e à oferta de políticas públicas (GIBSON; CALVO; FALLETI, 2003) ${ }^{5}$, como pode ser observado na Tabela 1.

Cada política específica engendrou um tipo de relação entre os entes federados, que, no caso brasileiro, envolve uma complexidade a mais por conta da tripla soberania (ARRETCHE, 2005), produzindo significado e conteúdo distintos, com diferentes resultados para a política pública ${ }^{6}$, seja pela descentralização política e autonomia de agenda, seja pela descentralização fiscal e capacidade de arrecadação. No caso do PST, governo central e governos subnacionais podem atuar de forma cooperativa ou concorrencial.

A desigualdade socioeconômica é o ponto de partida para o debate federalista brasileiro e sua diminuição é o projeto a ser perseguido pelo Estado. A Constituição de 1988 colocou como objetivo para o fortalecimento da federação a promoção de um maior equilíbrio entre os entes constitutivos (SOUZA, 2005). Há uma tensão permanente no estado federativo pela distribuição/redistribuição de poder e de recursos que não estão associados à eficiência dos governos subnacionais. Essa distribuição/redistribuição ganha uma dinâmica ainda mais complexa, no caso brasileiro, por conta da elevação do município a membro da federação. Dinâmicas de cooperação, disputas, consentimento e barganhas são produtoras de uma complexa engenharia política (ALMEIDA, 1995; RODDEN, 2005; SOUZA, 2005). Esse cenário aponta para relações intergovernamentais altamente competitivas, vertical e horizontalmente (SOUZA 2005).

Outra marca de nosso federalismo é sua descentralização, convivendo ao lado de tendências centralizadoras (ALMEIDA, 2005). A Constituição de 1988, de forte viés municipalista - aspecto descentralizador -, transferiu capacidade decisória, funções e recursos às instâncias subnacionais. Ele, o município, foi o principal beneficiário desse movi-

\footnotetext{
${ }^{5} \mathrm{~A}$ experiência internacional aponta que as clivagens étnicas e religiosas, produtoras de desigualdades, têm sido uma das principais preocupações na constituição do federalismo. No Brasil, segundo Arretche (2010), é a clivagem econômica que melhor explica as variações de nosso federalismo.

${ }^{6}$ Eles podem significar diversidade, diferença por concorrência ou desigualdade, conforme o modelo analítico utilizado (ARRETCHE, 2010).
} 
mento $^{7}$. Havia uma expectativa de que a descentralização melhoraria o resultado da política pública de forma a diminuir as desigualdades intrarregionais (BARACHO, 2000). No plano nacional, a crise do regime militar e a transição democrática geraram poderosas correntes descentralizadoras que foram associadas à democracia, à cidadania e à diminuição das desigualdades (ALMEIDA, 1995; ARRETCHE, 2005). No plano internacional, pressionada por uma maior eficiência dos governos, a descentralização estava associada ao paradigma da modernização gerencial (MELO, 1996). Esses dois movimentos acabaram por dar força a essa ideia, que acabou por criar dificuldades ao discurso e à prática centralizadora, elevando os custos da recentralização.

Porém, a consequência não esperada do processo de descentralização brasileira acabou por desnudar seus limites, principalmente aqueles associados à manutenção ou ao aprofundamento da desigualdade regional, como pode ser observado no Gráfico 1. São eles: a ambiguidade de competências entre as três esferas de governo, que produziu, em determinadas áreas, imobilismo; a baixa qualificação da burocracia; uma descentralização fiscal que dificultou a coordenação de certas políticas, de forma a garantir maior equidade entre os entes federativos; e, vulnerável às pressões advindas das elites locais, o clientelismo (MELO, 1996).

\section{Gráfico 1 - Distribuição regional da adesão das prefeituras ao PST de 2003 a 2012}

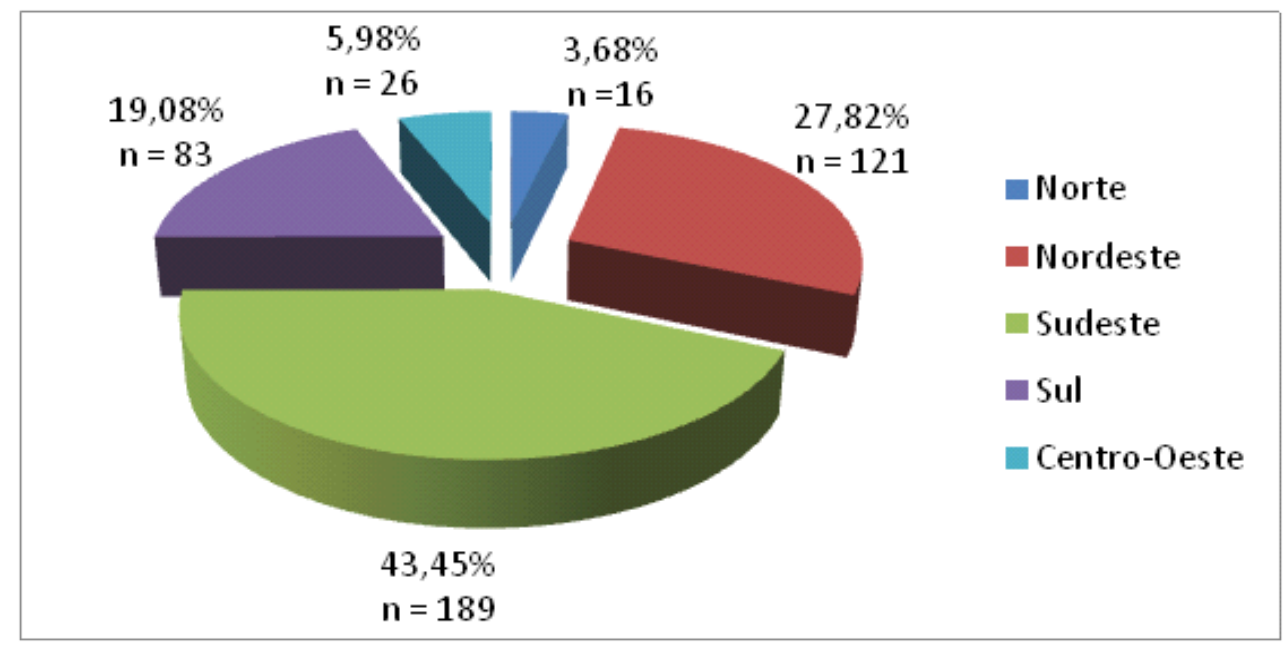

Fonte: Dados do Programa Segundo Tempo/Ministério do Esporte (2013).

Após dez anos de implementação, observa-se a fraca coordenação entre os entes federados (especialmente entre o governo federal e as prefeituras) e a consequente manutenção dos parâmetros de desigualdade (SOUZA, 2001; ARRETCHE, 2007). Affonso (1996) não interpreta a descoordenação como uma variável interveniente na manutenção

\footnotetext{
${ }^{7}$ Longe de ser uma idiossincrasia, a descentralização em direção aos municípios pode ser interpretada como o resultado da experiência acumulada pelos atores políticos municipais (na maior parte dos municípios), que durante o regime militar acumularam experiência política e administrativa (ALMEIDA; CARNEIRO, 2003).
} 
do cenário de desigualdade, mas como uma característica do modelo de descentralização brasileira que produz resultados políticos desiguais.

Uma análise mais acurada do desempenho dos governos é dependente dos arranjos institucionais e setoriais de uma dada política (ARRETCHE, 2003; ALMEIDA, 2005). A complexidade das relações federativas interage com diferentes fenômenos e produz resultados diferenciados na distribuição das políticas públicas também na realidade estadual. Como pode ser observado na Tabela 2, apenas oito estados conseguiram que mais de 10\% (que poderia ser um patamar mínimo de difusão) de seus municípios aderissem ao PST ao longo dos dez anos aqui analisados. A Região Sudeste foi a que obteve o melhor resultado, com três estados ultrapassando a barreira dos 10\%; e na região CentroOeste nenhum estado conseguiu ultrapassar essa barreira. De qualquer forma, o programa apresentou um desempenho bastante irregular na difusão via convênio com prefeituras e os estados apresentaram desempenhos muito distintos.

Tabela 2 - Percentual de difusão do PST entre as prefeituras por estados

\begin{tabular}{cc||cc||cc||cc||cc} 
UF & $\%$ & UF & UF & UF & UF & $\%$ & UF & $\%$ \\
AC & 0 & TO & 1,44 & PE & 4,86 & RJ & $\mathbf{1 9 , 5 6}$ & MS & 3,84 \\
AM & 4,84 & AL & 2,94 & PI & 3,57 & SP & $\mathbf{1 4 , 1 1}$ & MT & 5,67 \\
AP & $\mathbf{1 8 , 7 5}$ & BA & $\mathbf{1 0 , 3 1}$ & RN & $\mathbf{1 4 , 9 7}$ & PR & $\mathbf{1 0 , 5}$ & \\
PA & 3,49 & CE & 9,78 & SE & 2,67 & RS & 6,05 & \\
RO & 1,92 & MA & 1,38 & ES & $\mathbf{1 4 , 1 0}$ & SC & 3,75 & \\
RR & $\mathbf{1 3 , 3 3}$ & PB & 4,84 & MG & 8,09 & GO & 6,1 &
\end{tabular}

Fonte: Programa Segundo Tempo/Ministério do Esporte (2013).

Temos assistido, pelo menos em termos de políticas de esporte, cada vez mais, ao protagonismo do governo federal na formulação de políticas públicas (efeito centralizador), que se tornam mais e mais necessárias diante da falta de recurso dos governos subnacionais, dos (não) ganhos eleitorais que uma política que congrega esporte e criança pode ensejar ${ }^{8}$ e da diferenciação do valor que a política de esporte para criança tem em cada agenda intergovernamental.

A cooperação pode se dar por meio da produção de um pacote de incentivos de forma a seduzir ou mobilizar a atenção dos governos subnacionais, principalmente para aqueles mais vulneráveis. São esses que possuem mais dificuldades na implementação de políticas próprias.

Porém, um conjunto de variáveis intermediárias que se coloca entre o governo federal e o beneficiário do programa produz dinâmicas diferenciadas na implementação da política pública. Após experimentar dez anos de implementação do Programa Segundo

\footnotetext{
${ }^{8}$ Para análise da participação dos partidos e coalizões na difusão do PST, ver Santos (2012).
} 
Tempo (2003 a 2012), torna-se importante analisar as consequências do modelo desenhado de descentralização das ações pelo Ministério do Esporte na diminuição das desigualdades regionais de acesso a esse bem social, tendo em vista a importância do programa para o desenvolvimento da criança.

Observando o desempenho dos municípios mais vulneráveis ${ }^{9}$ na adesão ao programa, percebe-se a grande dificuldade para alcançar os escolares dessas cidades, que representam $41,15 \%$ delas. Essa distribuição não se dá de forma equânime no território nacional. A Região Nordeste é responsável por $72,14 \%(\mathrm{n}=1652)$ das cidades no nível mais elevado de exclusão; a Região Norte, por $13,89 \%(\mathrm{n}=318)$; a Região Sudeste, por $10,44 \%(n=239)$; a Região Sul, por $1,57 \%(n=36)$; e a Região Centro-Oeste, por $1,97 \%$ $(\mathrm{n}=45)$. Como podemos perceber, a Região Nordeste monopoliza o maior número de cidades em exclusão severa.

Apenas 4,59\% $(n=105)$ dos municípios nesse nível de exclusão conveniaram com o programa. A desassistência de 2.185 municípios com o programa colabora para a amplificação de sua vulnerabilidade na medida em que não empreendem esforços para garantir melhores condições de bem-estar para suas crianças. A região que melhor conseguiu adesão de seus municípios mais vulneráveis foi a Sul, com 5,55\% $(\mathrm{n}=2)$; a segunda maior difusão entre esses municípios foi na região Nordeste, com 5,15\% $(\mathrm{n}=85)$; seguidos das regiões Sudeste, 4,6\% $(\mathrm{n}=11)$, Centro-Oeste, $4,44 \%(\mathrm{n}=2)$, e Norte, $1,57 \%(\mathrm{n}$ $=5$ ). Nenhuma região conseguiu atingir, nos dez anos aqui analisados, $10 \%$ dos municípios mais vulneráveis.

Como a difusão ${ }^{10}$ do PST segue o modelo de descentralização por demanda (é dependente de convênios com parceiros), não é possível obrigar os municípios mais vulneráveis a aderirem ao programa. Tudo indica que, para esse grupo de proponentes (as prefeituras), o pacote de incentivos não é atraente, aliado ao fato de esporte e atenção à criança não serem plataformas eleitorais importantes. Portanto, a grande questão é se esse modelo de descentralização por demanda é suficiente para que se obtenham resultados redistributivos (atender a regiões mais vulneráveis), principalmente diante da autonomia política do poder local, das dificuldades operacionais à descentralização e dos patamares existentes de políticas locais de democratização do esporte. Pelo que foi apresentado até aqui, não.

\section{Conclusões}

É indiscutível a importância de programas que buscam ampliar o bem-estar infantil e juvenil, como o PST. Também é indiscutível que as prefeituras, principalmente as mais vulneráveis, possuem muitas dificuldades para, com recursos próprios, promoverem o desporto educacional. Esse cenário, por si só, já deveria garantir uma difusão do programa para todos os estados, o que de fato aconteceu; para todas as prefeituras, o que fi-

\footnotetext{
${ }^{9}$ Para essa análise, estamos utilizando a classificação de vulnerabilidade trazida por Pochmann e Amorim (2005). A exclusão severa refere-se ao seu pior estágio.

${ }^{10}$ Para análise do tema da difusão, no sentido de compreender como uma política vai se reproduzindo em outros ambientes ao longo do tempo, ver Berry e Berry (1999).
}

Pensar a Prática, Goiânia, v. 17, n. 4, out./dez. 2014 
cou muito longe de acontecer; e para as prefeituras mais vulneráveis, o que logrou resultados inexpressíveis.

Analisando esse resultado pela perspectiva federalista, podemos inferir que os incentivos à descentralização são muito tímidos, não mobilizando atenção dos gestores municipais. Nesse caso, a desatenção dos gestores compromete o bem-estar infantil e juvenil e promove o acirramento da desigualdade de acesso ao desporto educacional e à melhoria da qualidade de vida. A temática é envolvente e suscita novas pesquisas, visto que precisamos compreender melhor as motivações que levam os municípios, principalmente os mais vulneráveis, a não aderirem ao programa.

\title{
PROGRAM "SEGUNDO TEMPO" AND THE ROLE OF CITY GOVERNMENT IN ITS DIFFUSION
}

\begin{abstract}
Ten years after the implementation of the Program "Segundo Tempo" by the Ministry of Sports, and given its importance as a policy associated to childhood and youth well-being, it comes necessary to examine the role of city government in its diffusion - which is the main goal of the present paper. The study here, of descriptive nature, aimed to contemplate regional performance and the participation along with vulnerable cities. The results indicate that the incentive to decentralization is still discreet, not notable enough to foster municipal representatives' attention. In such case, this lack of attention compromises childhood and youth well-being as well as the improvement in life quality and promotes the aggravation of inequality regarding access to educational sports.

Keywords: Public Policy. Sport. Implementation.

\section{PROGRAMA "SEGUNDO TEMPO" Y EL PAPEL DE LA DIFUSIÓN EN EL MUNICIPIO}

\section{Resumen}

Pasados diez años de implementación del Programa "Segundo Tempo", por el Ministerio de Deporte, y, dada su importancia como uno de los padres de la política de bienestar de niños y jóvenes, es necesario examinar el papel de los gobiernos en su difusión, el objetivo principal de este artículo. El estudio, el análisis descriptivo, trató de contemplar el desempeño regional y la participación con los municipios vulnerables. Los resultados indican que los incentivos para la descentralización presentan todavía muy tímida, no captar la atención de los gestores municipales. En este caso, la falta de atención de los directivos comprometidos niño y el bienestar juvenil y promover la intensificación de la desigualdad en el acceso a la educación y el deporte en la mejora de la calidad de vida.

Palabras-claves: Política Pública. Sport. Implementación. 


\section{Referências}

AFONSO, J. R. R.; LOBO, T. Descentralização fiscal e participação em experiências democráticas retardatárias. Planejamento e Políticas Públicas, Brasília, n. 14, p. 3-36, 1996.

ALMEIDA, M. H. T. Federalismo e políticas sociais. Revista Brasileira de Ciências Sociais, São Paulo, v. 10, n. 28, p. 88-108, 1995.

ALMEIDA, M. H. T. A política social no Governo Lula. Novos Estudos CEBRAP, São Paulo, n. 70, p. 7-17, 2004.

ALMEIDA, M. H. T. Recentralizando a federação? Revista Sociologia e Política, Curitiba, v. 24, p. 29-40, jun. 2005.

ALMEIDA, M. H. T.; CARNEIRO, L. P. Liderança local, democracia e políticas públicas no Brasil. Opinião Pública, Campinas, v. 9, n. 1, p. 124-147, 2003.

ALVES, J. A.; PIERANTI, O. P. O Estado e a formação de uma política nacional de esporte no Brasil. RAE Eletrônica, São Paulo, v. 6, n. 1, Art. 1, jan./jun. 2007.

ARRETCHE, M. Dossiê agenda de pesquisa em políticas públicas. Revista Brasileira de Ciências Sociais, São Paulo, v. 18, n. 51, p. 7-9, fev. 2003.

ARRETCHE, M. Quem taxa e quem gasta: a barganha federativa na federação brasileira. Revista de Sociologia Política, Curitiba, n. 24, p. 69-85, jun. 2005.

ARRETCHE, M. A agenda institucional. Revista Brasileira de Ciências Sociais, São Paulo, v. 22, n. 64, p. 148-151, 2007.

ARRETCHE, M. Federalismo e igualdade territorial: uma contradição em termos? Dados, Rio de Janeiro, v. 53, n. 3, p. 587-620, 2010.

BARACHO, M. A. P. A importância da gestão de contas públicas municipais sob a premissa da governance e accountability. Revista do Tribunal de Contas do Estado de Minas Gerais, v. 34, n. 1, p. 129-161, jan./mar. 2000.

BERRY, F. S.; BERRY, W. Innovation and diffusion models in policy research. In: SABATIER, P. (Ed.). Theories of the policy process. Boulder: Westview, 1999. p. 169200.

BOURDIEU, P. Como é possível ser esportivo. In: BOURDIEU, P. Questões de sociologia. Rio de Janeiro: Marco Zero, 1983. p. 136-153. 
FERREIRA, H.; CASSIOLATO, M.; GONZALES, R. Uma experiência de desenvolvimento metodológico para avaliação de programas: o modelo lógico do Programa Segundo Tempo. Brasília: IPEA, 2009. (Texto para Discussão n. 1369).

GIBSON, E. L.; CALVO, E. F.; FALLETI, T. G. Federalismo realocativo: sobre-representação legislativa e gastos públicos no hemisfério ocidental. Opinião Pública, Campinas, v. 9, n. 1, p. 98-123, 2003.

GUARÁ, I. É imprescindível educar integralmente. Cadernos Cenpec, São Paulo, v. 1, n. 2, p. 15-24, 2006.

MEDEIROS, M.; DINIZ, D. Paradigmas de justiça distributiva em políticas sociais. Revista de Estudos Universitários, Sorocaba, v. 34, p. 19-31, 2008.

MELO, M. A. Crise federativa, guerra fiscal e "hobbesianismo municipal" efeitos perversos da descentralização? São Paulo em Perspectiva, São Paulo, n. 10, v. 3, p. 11-20, 1996.

POCHMANN, M.; AMORIM, R. (Org.). Atlas da exclusão social no Brasil. São Paulo: Cortez, 2005.

RAWLS, J. Justiça como equidade: uma concepção política, não metafísica. Lua Nova, São Paulo, n. 25, p. 25-29, 1992.

REZENDE, F. C. Descentralização, gastos públicos e preferências alocativas dos governos locais no Brasil. Dados, Rio de Janeiro, v. 40, n. 3, p. 413-440, 1997.

RIBEIRO, L. C. Q. et al. Níveis de integração dos municípios brasileiros em Rms, RIDEs e AUs à dinâmica da metropolização. Observatório das Metrópoles, 2012.

RODDEN, J. Federalismo e descentralização em perspectiva comparada: sobre significados e medidas. Revista Sociologia e Política, Curitiba, v. 24, p. 9-27, jun. 2005.

SANTOS, E. S. O papel dos partidos políticos na difusão do Programa Segundo Tempo. Licere, Belo Horizonte, v. 15, p. 1-26, 2012.

SEILBEL, E. O declínio do welfare state e a emergência do estado prisional: tempos de um novo puritanismo? Civitas, Porto Alegre, v. 5, n. 1, p. 93-107, jan./jun. 2005.

SOARES, M. M. Federação, democracia e instituições políticas. Lua Nova, São Paulo, n. 44, p. 137-163, 1998.

SOUZA, Celina. Federalismo e gasto social no Brasil: tensões e tendências. Lua Nova, São Paulo, n. 52, p. 5-28, 2001. 
SOUZA, C. Federalismo, desenho constitucional e instituições federativas no Brasil pós1998. Revista Sociologia e Política, Curitiba, v. 24, p. 105-121, jun. 2005.

ZAHARIADIS, N. The multiples streams framework: structure, limitations, prospects. In:

SABATIER, P. (Org.) Theories of the policy process. Cambridge, MA: Westriew Press, 2007. p. 65-92.

Recebido em: 25/04/2013

Revisado em: 15/07/2014

Aprovado em: 14/09/2014

Endereço para correspondência:

jeantecem2010@hotmail.com

Jean Carlo Andrade

Universidade Federal do Vale do São Francisco, Colegiado de Educação Física.

Av. José de Sá Maniçoba, S/N Centro

56304917 - Petrolina, PE - Brasil

Pensar a Prática, Goiânia, v. 17, n. 4, out./dez. 2014 